\title{
Successful Therapeutic Management of Babesiosis in a Labrador Dog along with Blood Transfusion
}

\author{
Kanwarpal Singh Dhillon ${ }^{1 *}$, Simran Jot Kaur ${ }^{2}$, Alamjit Singh ${ }^{3}$ and Mukal Gupta ${ }^{3}$ \\ ${ }^{1}$ Department of Veterinary Medicine, Khalsa College of Veterinary and Animal Sciences \\ (KCVAS), Amritsar, Punjab, India \\ ${ }^{2}$ Paras Nutrition Private Limited, Moga, Punjab, India \\ ${ }^{3}$ Khalsa College of Veterinary and Animal Sciences, Amritsar, Punjab, India
}

*Corresponding author

\section{A B S T R A C T}

Keywords

Babesiosis, Anemia, Icterus, Imidocarb, Blood transfusion, Labrador

\section{Article Info}

Accepted: 15 April 2020 Available Online: 10 May 2020
A two and a half year old male Labrador dog was brought with history of in appetence, pyrexia, weakness, vomiting, blood in urine and lateral recumbencysince a week. Clinical examination revealed icteric visible mucousmembrane, dehydration, high fever $\left(105^{\circ} \mathrm{F}\right)$, increased respiratory rate and enlarged superficial lymph nodes with presence of ticks on body surface. Urinalysis revealed haemoglobinuria. Haematological findings revealed severe anemia $(\mathrm{Hb}-2.2 \mathrm{~g} / \mathrm{dl})$ and thrombocytopenia $\left(88 \times 10^{5} / \mu \mathrm{l}\right)$. Serum biochemistry showed elevated BUN $(102 \mathrm{mg} / \mathrm{dl})$, creatinine $(3.2 \mathrm{mg} / \mathrm{dl})$, ALT $(160 \mathrm{U} / \mathrm{L})$ and total bilirubin $(2.8 \mathrm{mg} / \mathrm{dl})$. Microscopic examination revealed Babesia gibsoni in RBC's. On the basis of history, clinical findings and laboratory examination the case was diagnosed as Babesiosis. The dog was treated with Imidocarbdipropionate, supportive therapy and life-saving blood transfusion.

\section{Introduction}

The occurrence of canine babesiosisis on an increase and several cases are being reported from all over India. It is the diseased state caused by protozoal parasites of the genus Babesia. The most common mode of transmission in dogs is tick bite. Babesia piroplasms infect and multiply in RBCs, resulting in both direct and immune mediated hemolytic anemia. Other common signs include high fever, pale mucous membranes, jaundice, lack of energy, vomiting, constipation, enlarged abdomen and discolored stool.

Blood transfusions in veterinary medicine have become increasingly more common and are an integral part of lifesaving and advanced treatment of the critically ill animals. 
Common situations involving transfusions are life-threatening anemia from acute hemorrhage or surgical blood loss, hemolysis from drugs or toxins, immune-mediated diseases, haemoprotozoal diseases, severe non-regenerative conditions and neonatal isoerythrolysis. It is indicated in situation where packed cell volume (PCV) is less than $15 \%$ and haemoglobin concentration below 5 gm\% (Tufani et al., 2004).

Whole blood is indicated in patients that requires several blood components or has acutely lost more than $50 \%$ of its total blood volume, in order to replace both oxygencarrying capacity and oncotic activity (Lanevschi and Wardrop, 2001). The present paper reports successful therapeutic management with fresh whole blood transfusion in life threatening acute anemia induced by Babesiosis in a Labrador dog.

History, laboratory investigation and diagnosis

A two and a half year old male Labrador dog (25 kg b.wt.) was presented with history of inappetence, pyrexia, weakness, vomiting, blood in urine and lateral recumbency (Fig. 1) since a week. The animal was repeatedly treated by local veterinarians without success. The dog was vaccinated and dewormed regularly. Clinical examination revealed icteric visible mucous-membrane (Fig. 2), dehydration, high rise of temperature $\left(105^{\circ}\right.$ F), increased respiratory rate and enlarged superficial lymph nodes with presence of ticks on body surface. Aseptically, urine was collected by catheter and the sample was immediately transferred into sterilized tubes for investigation.

Urinalysis (centrifugation) of sample taken was found haemoglobinuria (Fig.3) Blood samples were checked for routine hematological and biochemical profiles.
Haematological findings revealed severe anemia (Hb- $2.2 \mathrm{~g} / \mathrm{dl}, \mathrm{PCV}-10 \%$, TEC- 10.2 $\times 10^{6} / \mu 1$, TLC- $7.2 \times 10^{3} / \mu 1$, N- $62 / \mu 1, \mathrm{~L}-34 / \mu 1$, E- $4 / \mu \mathrm{l}$ ) along with thrombocytopenia (PLT$\left.88 \times 10^{5} / \mu \mathrm{l}\right)$. Serum biochemistry showed elevated blood urea nitrogen (BUN) (102 $\mathrm{mg} / \mathrm{dl})$, creatinine $(3.2 \mathrm{mg} / \mathrm{dl})$, alanine aminotransferase (ALT) $(160 \mathrm{U} / \mathrm{L})$ and total bilirubin $(2.8 \mathrm{mg} / \mathrm{dl})$. Peripheral blood smear made from ear tip, stained with Giemsa stain examined under oil immersion (x100) revealed Babesia gibsoni in RBC's (Fig. 4). Based on tick history, clinical findings and microscopic examination, the case was diagnosed as canine Babesiosis.

\section{Treatment and Discussion}

The treatment was initiated withInj. Dextrose (20\%) @2 ml $/ \mathrm{kg}$ IV OD for 5 days,Inj. Imidocarbdipropionate (Babimido) @6mg/kg SC once, Inj. Vitamin B-complex @3ml IM OD for 5 days, Tab. Pantoprazole @ $1 \mathrm{mg} / \mathrm{kg}$ PO OD for 7 days, Tab. Prednisolone (Wysolone) @ $1 \mathrm{mg} / \mathrm{kg}$ PO OD for five days along with liver tonic (Hepamust) @2 tsf.PO BID for 7 days.

Since clinical signs and hematological parameters suggested anemia, immediate whole blood transfusion was done on the $1^{\text {st }}$ day as emergency treatment. For blood transfusion a three years old healthy Labrador dog (30 kg b.wt.) of same owner was selected as donor and detailed hematological indices were estimated and blood smear examination for hemaprotozoa was also carried out. Major and minor cross matching of donor and recipient was done according to the method of Lanevschi and Wardrop (2001). The volume of required blood was calculated on the basis of formula given by Sackmen (1998).

Blood volume to be infused $=$

Body wt. (kg) x 90x (Required PCV-Recipient's PCV) (Donor's PCV) 
After calculation $350 \mathrm{ml}$ of blood was collected from jugular vein in citratephosphate-dextrose-adenine bag (Fig. 5) and blood transfusion was done on emergency as per standard procedure (Fig. 1). Inj. Pheniramine maleate @ $1 \mathrm{ml}$ IM and Inj. Dexamethasone @1mg/kg IM were given to recipient before administrating the blood to avoid the transfusion reaction. The animal was still observed continuously for restlessness, excitement, tachycardia, hyperpnoeaetc. To rule out the adverse reaction during blood transfusion. After blood transfusion, $3^{\text {rd }}$ day onwards dog showed improvement in clinical signs and haematobiochemical values. The owner was advised to continue liver tonic for next ten days and follow up thereafter a week. After ten days owner informed that the dog has completely recovered (Fig. 6) and thriving well.

Babesia species are intra-erythrocytic parasites transmitted by ticks. In dogs, the two described species are - Babesia canis, a large species and Babesia gibsoni, a small one. The diagnosis of Babesia spp. infection is usually based on detection of merozoites in peripheral blood smear. The smears are usually prepared with blood taken from ear margin capillary bed.

In the present case, the clinical symptoms observed in this study were fever, anorexia, dullness, hemoglobinuria, icterus, anemia and thrombocytopenia which were also reported by (Peterson, 2006; Nelson and Couto, 2009). The values of $\mathrm{Hb}, \mathrm{PCV}, \mathrm{TEC}$ and total platelet count were significantly decreased in dog which came to normal after treatment.

The same has been observed by (Kshama, 2017; Venkatesakumar et al., 2018). The elevated BUN and creatinine in our case were mainly due to babesiosis which causes damage torenal cells due to development of refractory hypotension resulting in reduced renal tissue perfusion and glomerular filtration rate (Zygner and Wedrychowicz, 2009; Venkatesakumar et al., 2018). Several mechanisms are said to contribute to anemia in babesiosis and these include immunemediated destruction of erythrocytes, increased erythrocyticosmotic fragility, direct injury to erythrocytes by the parasites and oxidative injury (Birkenheuer, 2014). Thrombocytopenia observed in present case was in accordance with (Harrus et al., 1997; Venkatesakumar et al., 2018).

Treatment with immuno-suppressive doses of glucocorticoids is necessary along with antibabesial therapy to manage haemolyticanemias (Birkenheuer, 2012). Imidocarbdipropionate is the active agent against $B$. canis and it can eliminate $B$. canis for upto four weeks following treatment and can prevent infection upto 6 weeks. It however does not clear $B$. gibsoni infection but only reduces the mortality and morbidity (Raskin, 2006; Birkenheuer, 2014). Hence it can be used as an alternate therapy when the drug of choice for B. gibsoni, Atovaquone is not available.

There are currently no alternative oxygencarrier products, such as free hemoglobin, available for veterinary use. Whole blood transfusion has provided coagulation factors, plasma proteins, some white cells and platelets. So dogs with transfusions achieve higher PCVs and had better oxygen-carrying capacity to overcome the underlying disease (Cunha, 2011).

The recommended dose is $20 \mathrm{ml} / \mathrm{kg}$ to elevate the hematocrit by 10\% (Abrams-Ogg, 2000). After the treatment all parameters came to their normal values with complete cessation of all clinical signs. Thus, blood transfusion along with Imidocarb treatment to affected dogs found best by decreasing the severity and favoring early recovery of dog. 


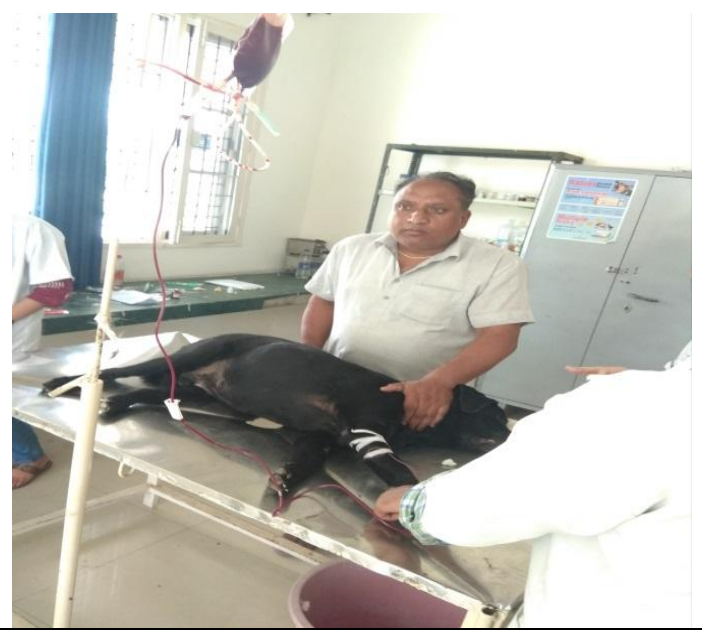

Fig.1 Dog undergoing blood transfusion

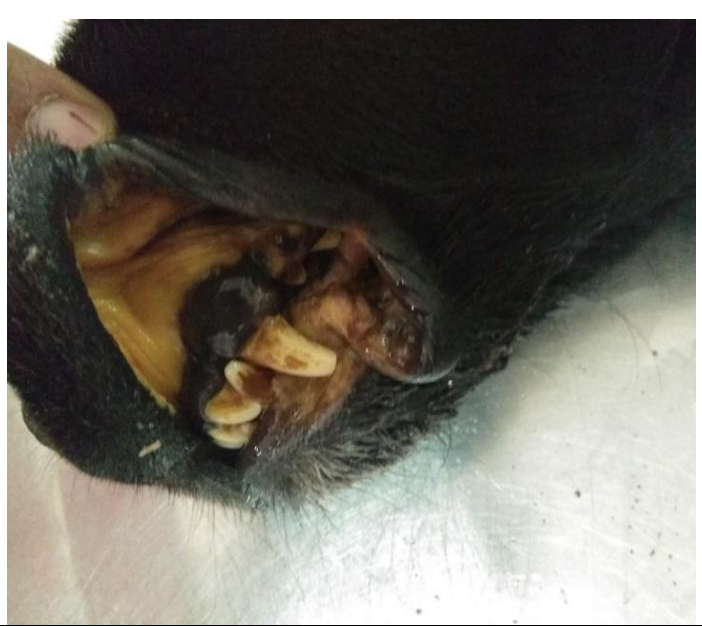

Fig.2 Icteric mucous membrane

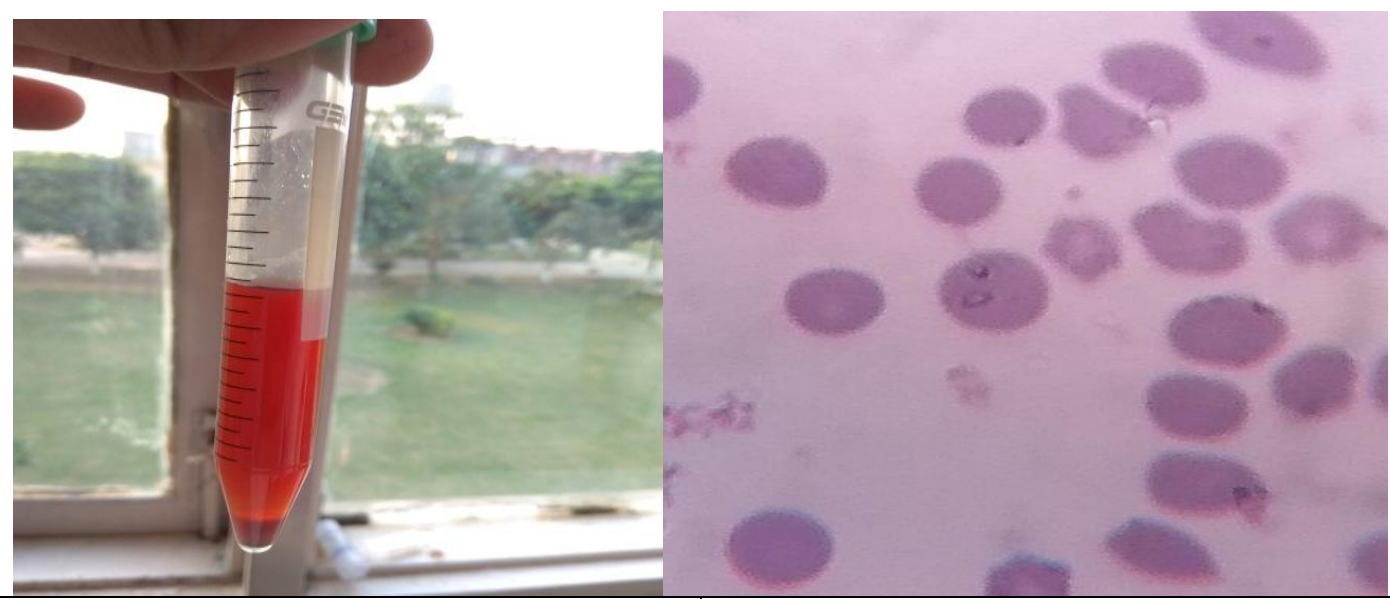

Fig.3 Sample after centrifugation showing haemoglobinuria

Fig.4 Blood smear examination indicating presence of Babesia gibsoni on blood cell

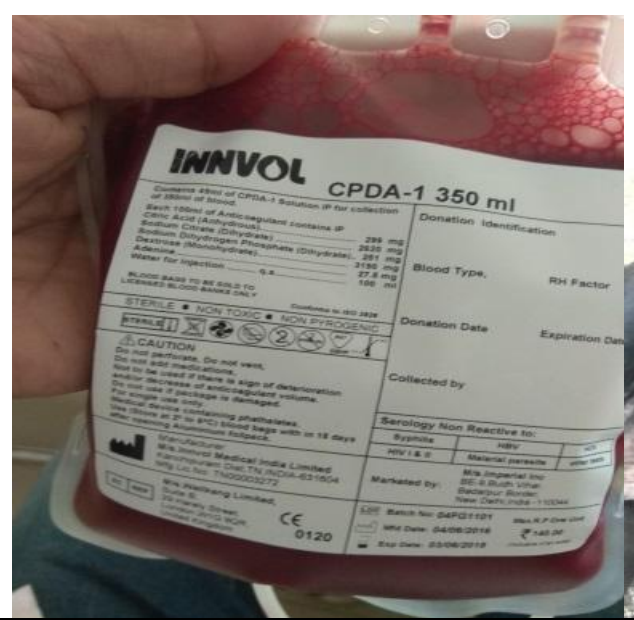

Fig.5 Citrate-Phosphate-Dextrose Adenine blood bag

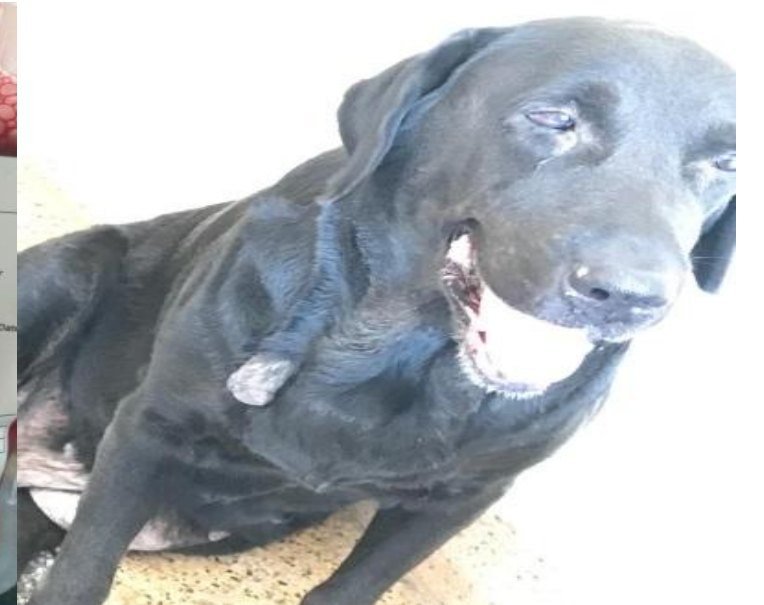

Fig.6 Recovered dog after treatment 
A case of Babesiosis in an adult male Labrador dog and its successful treatment with Imidocarbdipropionate, supportive therapy and life-saving blood transfusion has been discussed.

\section{Acknowledgements}

The author is thankful to the Principal, KCVAS, Amritsar for providing necessary facilities to carry out this study.

\section{References}

Abrams-Ogg, A. 2000. Practical blood transfusion. In: BSAVA Manual of Canine and Feline Haematology and Transfusion Medicine. British Small Animal Association, England, 263-307.

Birkenheuer, A.J. 2012. Babesiosis: In: Infectious Diseases of the Dog and Cat, edited by Greene. C.E. $4^{\text {th }}$ Edn. Elsevier Publication, USA, Pp. 771-84.

Cunha, L.F.G., Ferreira A.C.S., and Ferreira R.M.R.F. 2011.Whole blood transfusion in small animals: indications and effects. Annals of the Brazilian Academy of Sciences. 83(2):611-617.

Harrus, S., Aroch, I., and Lavy, E. 1997. Clinicalmanifestations of infectious canine cyclicthrombocytopenia. Vet. Rec.141: 247.

Kshama, M.A., Mamatha G.S., and Puttalakshmamma G.C. 2017.
Successful Treatment of Babesia gibsoni infection in a Splenectomized dog. Intas Polivet. 18 (1): 183-184.

Lanevschi, A., and Wardrop, K.J. 2001. Principles of transfusion medicine in small animals. Can Vet. J. 42: 447-54.

Nelson, R.W., Couto C.G. 2009. Polysystemic Protozoal Infections. In: Small Animal Internal Medicine. $4^{\text {th }}$ Edn, $1360-1361$.

Peterson, J.L. Hematology/Oncology. In: Saunders Manual of Small Animal Practice. $3{ }^{\text {rd }}$ Edn, Elsevier, St. Loius, Missouri, 2006, 236-237.

Raskin, R.E. 2006. Erytrocytes, leckocytes and platelets. In: Saunders Manual of Small Animal Practice. $3^{\text {rd }}$ Edn, Birchard and Sherding. Saunder Elsevier, USA, 236-37.

Sackmen, J. 1998. Decision making in fluid therapy. In: Textbook of Canine Medicine and Therapeutics. In Gorman, N.T., $4^{\text {th }}$ Edn., Blackwell Science Ltd., Oxford.

Tufani, N.A., Shekhar, P., Haque, S., Kumar, P. and Thakur, S.K. 2004. Blood transfusion in anemic dog and its management. IntasPolivet, 5:100-102.

Venkatesakumar, E., Kumar V., and Ramprabhu R. 2018. Diagnosis and Management of Concurrent Ehrlichiosis and Babesiosis in a Dog.IntasPolivet. 19(2): 267-268.

\section{How to cite this article:}

Kanwarpal Singh Dhillon, Simran Jot Kaur, Alamjit Singh and Mukal Gupta. 2020. Successful Therapeutic Management of Babesiosis in a Labrador Dog along with Blood Transfusion. Int.J.Curr.Microbiol.App.Sci. 9(05): 2058-2062. doi: https://doi.org/10.20546/ijcmas.2020.905.235 